\title{
Antidisciplina, \\ Transdisciplina y \\ Redisciplinamientos \\ del Saber ${ }^{1}$
}

por Nelly Richard ${ }^{2}$

Vuelvo sobre la discusión entre trabajo intelectual y trabajo

académico: coinciden en parte... pero no son lo mismo. Vuelvo sobre la dificultad de instituir una real práctica de crítica cultural, que no debe tratar de reinscribirse en la metanarrativa del conocimiento alcanzado dentro de las instituciones. Vuelvo sobre teoría y po-

líticas, sobre las políticas de la teoría. No la teoría como voluntad de verdad, sino la teoría como un conjunto de conocimientos en pugnas, localizados y coyunturales.

\section{Stuart Hall}

unque todavía escasos y muchas veces precarios en sus realiza-
ciones, ciertos gestos destinados a modificar las reglas de con
figuración del saber tradicional buscan perfilarse en el contexto

1 El presente texto forma parte de un capítulo del libro "Residuos y Metáforas (Ensayos de crítica cultural sobre el Chile de la Transición) de la autora, quién tuvo la generosidad de autorizar la operación de reensamblaje de dicho material para que fuese incorporado al interior del corpus de la Revista Chilena de Temas Sociológicos.

2 La autora es crítica y ensayista, desde 1990 dirige la Revista de Crítica Cultural, hasta hace poco dirigió el Diplomado de Crítica Cultural de la Universidad Arcis y en 1996 obtuvo la beca Guggenheim. Es autora, entre otras publicaciones, de: Masculino/femenino (1993) y La insubordinación de los signos (1994). 
a descentrar los mecanismos de jerarquía y control del conocimiento oficial -pluralizando las formas y los estilos de hacer teoría- hablan de «miradas transversales que propician cruces inter y multidisciplinarios, así como puentes entre lo académico y las polifonías socio-culturales; de saberes que no están ni autorizados ni consolidados, sino más bien abiertos a las errancias crítico-creativas de los inestables y fluidos imaginarios de fin de siglo"4.

Pluralidad, movilidad y flexibilidad del conocimiento son algunos de los rasgos que estas prácticas del saber recientemente diseñadas oponen a la rigidez del formato académico tradicional, recurriendo a la transdisciplinariedad como vector experimental y creativo de reconfiguración de nuevos instrumentos teóricos para el análisis crítico de la cultura.

Los estudios culturales y la crítica cultural representarían dos nuevas prácticas que participan de esta misma búsqueda de transversalidad tanto en el rediseño de las fronteras del conocimiento académico (los estudios culturales) como en las rearticulaciones críticas del discurso teórico (la crítica cultural). Ambas prácticas -y las relaciones de diálogo, resistencia o cuestionamiento que las vinculan entre sí- invitan a una reflexión, necesaria de producirse hoy, que desborda el formato del saber universitario y del discurso académico para interrogar los bordes críticos del trabajo intelectual.

\section{Textos intermedios, saberes fronterizos}

¿A qué llamarle «crítica cultural' y cómo evitar que la repetición del nombre suene taxativamente a programa como si designara un modelo a aplicar supuestamente dotado de, una homogeneidad de forma y contenidos?

Aunque dejáramos en suspenso la definición de qué es la "crítica cultural" (primero, porque dicho término designa un conjunto variable de prácticas

3 A modo de ejemplos, quisiera mencionar el Programa Género y Cultura en América Latina de la Facultad de Filosofía y Humanidades de la Universidad de Chile y el Diplomado en Crítica Cultural de la Universidad Arcis, como dos espacios interesados en desobedecer los sistemas de fidelidad disciplinaria y en articular una tensión -política y teórica- entre las fronteras de la academia y saberes heterodoxos que provienen de otras partes.

4 Kemy Oyarzún, "Introducción", revista Nomadías, $N^{o}$ 1, Editorial Cuarto Pro-pio/PGAL, diciembre de 1996, Santiago, p. 7. 
y escrituras que no responden a un diseño uniforme y, segundo, porque no cerrar esta movilidad de posiciones diferenciadas que arma contrastes entre discursos heterogéneos contribuye a desalinear la voluntad académica de querer siempre ordenar tipologías y nomenclaturas), valdría la pena precisar algunos de los rasgos que, pese a esta heterogeneidad de formas y disimilitud de contenidos, comparten varios textos de hoy que suelen identificarse como textos de "crítica cultural"s : textos que se encuentran a mitad de camino entre el ensayo, el análisis desconstructivo y la crítica teórica, y que mezclan estos diferentes registros para examinar los cruces entre discursividades sociales, simbolizaciones culturales, formaciones de poder y construcciones de subjetividad.

Digamos, primero, que se trata de «textos que -sobre todo en su momento de producción y circulación - desbordan una inscripción fácil en la retícula del saber y que vindican para sí esa condición de margen. Margen respecto a los campos disciplinarios constituidos -sociología, psicoanálisis, semiología, antropología, teoría literaria, etc.- aun cuando se parasite de los conceptos generados en esos campos; se trata de textos animados por el propósito de desplegar -en un registro verbal que premeditadamente se aparta de las doxas institucionalizadas- una mirada conceptual sobre coyunturas significantes que, o bien: 1) no están analizadas todavía; 2) están consideradas hasta ahí según marcos discursivos cuyos presupuestos ideológicos no han sido sometidos a crítica; o bien 3) están excluidas de todo análisis por la acotación de campo reproducida inercialmente a través de la formación disciplinaria. Textos que se despliegan al margen del aval institucional, esto es, en cuyos enunciados no habla aún - a través de sus soportes, formatos, sintaxis y gramática- la institución convertida en sujeto, sino que, todo lo contrario, se definen ya en su cuerpo significante, en tensión crítica con ella"6

Los textos de crítica cultural serían entonces textos intermedios que no quieren dejarse localizar según los parámetros institucionales que definen el saber ortodoxo; textos que reivindican su im-propiedad en relación a las

5 Junto con insistir en el carácter provisorio y tentativo del término "crítica cultura" que designa un conjunto multiforme de textos imprecisos en sus contornos, prefiero dejar a la imaginación del lector la responsabilidad de elegir, dentro de las lecturas que conforman cada bibliografía, los textos que compartirían más felizmente algunos de los rasgos aquí descritos.

6 Carlos Pérez V., Introducción al Seminario de Crítica Cultural, Universidad Arcis, abril de 1997. 
disciplinas tradicionales y la noción tradicional de «disciplina» entendida como un corpus de enseñanza cuyas reglas de-especialización fijan y controlan la relación (disciplinaria, técnica y profesional) entre objetos, saberes y métodos ${ }^{7}$. Lejos de ser una disciplina, la crítica cultural sería una práctica, es decir, un modo de hacer, una forma de actuar, una estrategia de intervención teórico-discursiva que selecciona sus instrumentos críticos en función de la coyuntura de signos que se propone analizar y desmontar. «Hay una política de las armas en la crítica cultural, una política del recurso de que se echa mano postestructuralismo, semiología,

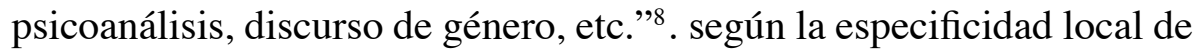
los materiales y de las significaciones a intervenir.

Ligado a esta dimensión coyuntural, deberíamos también enfatizar el carácter de intervención que anima el proyecto de la crítica cultural. No le bastaría a dicho proyecto analizar los textos de la cultura en su dimensión intradiscursiva, sino que buscaría siempre comprometer a su destinatario en un trabajo crítico de desmontaje y rearticulación del sentido para examinar las conexiones locales y específicas que unen los signos a sus redes político-institucionales. Se trataría de colocar bajo sospecha los resortes discursivos de las construcciones de poder que traman las distintas cadenas de producción y recepción sociales de los enunciados en circulación; de involucrar al lector en una tarea compartida de vigilancia crítica que le enseñe a desocultar los artificios de representación dominantes y a producir, a la vez, contralecturas susceptibles de impugnar su sistema de valores y de jerarquizaciones canónicas.

En una línea derivada del postestructuralismo, la crítica cultural trabajaría en politizar la cuestión del discurso haciéndolo ver como trama de violencia, control y lucha en torno a la autoridad simbólica del poder de la palabra y del control de la representación. Pero la crítica cultural no se conformaría con sólo desconstruir las figuras discursivas de imposición del sentido en las que las ideologías sociales basan su poder normalizador. Pretendería también descubrir y activar críticamente lo que se resiste a ellas-. la potencialidad discordante de las entrelíneas

7 Según M. Foucault: "una disciplina se define por un ámbito de objetos, un conjunto de métodos, un corpus de proposiciones consideradas verdaderas, un juego de reglas y de definiciones, de técnicas y de instrumentos". Michel Foucault, "El orden del discurso", Barcelona, Tusquets, 1973, p. 27

8 Willy Thayer, Introducción al seminario de Crítica Cultural, Universidad Arcis, abril de 1997. 
más rebeldes de los textos de la cultura que entran en disputa con sus relatos legitimadores ${ }^{9}$.

A la crítica cultural, le interesaría tomar partido a favor de las significaciones antihegemónicas -no centrales- que emergen de escrituras y lecturas en pugna con la tradición oficial, el canon dominante, la normativa institucional, y que apelan a una política y a una estética de los bordes, de los márgenes y de las fronteras. (Por eso las alianzas que suelen tejerse -en desorden de programas- entre la crítica cultural, la desconstrucción y la teoría feminista: por sus comunes propósitos de desorganizar las máquinas binarias que giran alrededor de una "función-centro" de la representación hegemónica para rescatar lo plural y diseminado que habitan, minoritariamente, en las franjas de exclusión y subalternidad de la geografía del conocimiento oficial).

Los estudios culturales -tal como han sido definidos ${ }^{10}$ - también se mueven en la dirección transdisciplinaria de un modelo de reorganización académica del conocimiento que incorpora saberes hasta ahora marginados por el canon de las disciplinas tradicionales. La crítica cultural y los estudios culturales compartirían un mismo interés por ciertas combinaciones teóricas que les sirven a ambos para analizar (y defender) representaciones sociales y formaciones de identidad habitualmente se-

9 Dice P. Bové: "la acción crítica no puede sólo descubrir y minar el discurso opresor, sino también abrir espacios de ayuda a otros para formar sus propias subjetividades en oposición a las definiciones discursivas e institucionales generadas y fijadas por las estructuras dominantes y sus agentes". Paul Bové, " $L a$ estela de la teoría”, Madrid, Cátedra 1992, p. 78.

10 Son múltiples y diversas las definiciones que se pueden proponer de este nuevo modelo de reorganización académica del conocimiento llamado "Estudios Culturales": un modelo ya ampliamente formalizado en la academia internacional (principalmente, anglo-norteamericana) y de creciente implementación en varias universidades latinoamericanas. A modo de referencia, ofrezco dos descripciones que definen el proyecto de los estudios culturales desde dos diferentes latitudes: J. Beverley habla de los "estudios culturales" como de "un programa vinculado más o menos directamente con la militancia política de los sesenta, la Nueva Izquierda, el marxismo althusseriano o neo - gramsciano, la teoría feminista y el movimiento de mujeres, el movimiento de derechos civiles, la resistencia contra las guerras coloniales o imperiales, la desconstrucción", John Beverley, "Estudios culturales y vocación política", en Revista de Crítica Cultural, $N^{o}$ 12, julio de 1996, Santiago, p. 46. Mientras Silvia Delfino se refiere a ellos en función de los problemas que permiten analizar: problemas relacionados con "vida cotidiana e información, géneros audiovisuales y consumo de bienes simbólicos, recorridos urbanos como transformaciones perceptivas, pasaje de la democracia de masas a un uso político de la visibilidad de las minorías o la proliferación de demandas por derechos localizados concretos", Silvia Delfino (comp.), "Prólogo" en La mirada oblicua: estudios culturales y democracia, Buenos Aires, La Marca, 1993, p. 5. 
gregadas por las jerarquías de la cultura oficial. Ambas prácticas estarían interesadas en provocar una «insurrección de los saberes sometidos» (Foucault) destinada a potenciar la fuerza de descentramiento de los márgenes y de las periferias que bordean la cultura institucionalizada. Pero quizás, mientras los estudios culturales defienden el objetivo práctico de rearticular universitariamente programas de transmisión de los nuevos conocimientos, la crítica cultural gozaría de una mayor libertad de movimiento para entrar y salir del mapa académico -para moverse en sus bordes- poniendo especialmente el acento en la transversalidad crítica de su práctica del texto.

Por un lado, los estudios culturales y la crítica cultural elaborarían una respuesta solidaria si los confrontáramos a la pregunta de cuáles prácticas son capaces de abrir nuevos contextos de descubrimiento que modifiquen el trazado de inclusión - exclusión del saber dominante, ya que ambos se inclinan hacia sujetos y objetos discriminados por el abusivo predominio de lo central (lo metropolitano, lo occidental, lo masculino, etc.). Pero a la crítica cultural le interesaría, además y sobre todo, preguntarse más específicamente cómo deben abordarse estos nuevos objetos (a través de qué nuevos registros de conocimiento y también de escritura) para que la relación entre teoría y novación pase por un cuestionamiento no sólo conceptual, sino también retórico de las formas de habla que sobredeterminan los saberes heredados de las disciplinas, ya que son estas formas las que los ponen en situación de «exclusión o inclusión, complicidad o resistencia, dominación o relajo, abstracción o coyunturalidad, monólogo o polílogo, quíetismo o activismo, mismedad u otredad, opresión o emancipación, centralización o descentralización» ${ }^{11}$ frente al lenguaje codificador del programa académico.

Frente a los estudios culturales básicamente preocupados de ampliar y diversificar los trazados universitarios del conocimiento, la crítica cultural acentuaría la necesidad de reflexionar no sólo sobre la formulación social de los nuevos objetos a teorizar (democracia, feminismo, globalización, ciudadanía, post - colonialismo, etc.), sino también sobre sus propios dispositivos de teorización: sobre lo que el uso de la teoría

11 Vincent Leitch, Cultural Cilticism, Literary teory, Poststructuralism, New York, Columbia University Press, 1992, p. 9. (La traducción es mía). 
moviliza y transforma en y de las redes del conocimiento disciplinario; sobre las respectivas posiciones de autoridad académico-institucionales que obedecen o desobedecen los textos según donde coloque la voz el saber crítico. Estas posiciones de voz, estos registros de habla definen y articulan las políticas de la escritura del texto crítico.

\section{La teoría como escritura}

El tema de las relaciones entre saber académico y des-academización del saber también pasa por esta cuestión de la escritura crítica, de las políticas del texto escrito. Sin embargo, dicho, tema es generalmente desatendido por los estudios culturales cuyo standard académico tiende a producir una suma uniforme de materiales investigativos -regidos por la operatividad tecnocultural del dato- que encuentra su símbolo desapasionado en el paper. La reducción funcionaria del Texto al paper ha roto el emblema de una densa tradición ensayística con el nuevo predominio de la investigación sociológica que sacrifica la espesura retórica y figurativa del lenguaje en el sentido (fuerte) de lo que Barthes llamaba «la teoría como escritura» ${ }^{12}$, es decir, la teoría que piensa sus formas y dice cómo se dice, para desinstrumentalizar el simple "referirse a» del saber práctico con palabras que retienen, en su urdimbre reflexiva, la memoria del deshacer y del rehacerse de la significación. Contra la funcionalidad del paper que predomina en los departamentos de estudios culturales donde se persigue la mera calculabilidad de la significación, la manipulabilidad de la información cultural para su conversión económica en un saber descriptivo, la «teoría como escritura" fantasea con abrir líneas de fuga por donde la subjetividad crítica pueda desviarse a recta del conocimiento útil para explorar ciertos meandros del lenguaje que recargan los bordes de la palabra de intensidad opaca.

Los estudios literarios, lo sabemos, se vieron bruscamente sacudidos por

12 Decía R. Barthes: "me pregunto si, en última instancia, no podría identificarse teoría y escritura. La escritura, en el sentido actual que puede concederse a la palabra, es una teoría. Tiene una dimensión teórica, y ninguna teoría debe rehusar la escritura, ninguna teoría debe moverse únicamente en el interior de una pura 'escribancia', es decir, desde una perspectiva puramente instrumental respecto al lenguaje... La teoría sería un lenguaje que... se observa a sí mismo en una especie de autocrítica permanente". Roland Barthes, en La teoría, varios autores, Barcelona, Anagrama, 1971, p. 9. 
el descentramiento de la ideología moderna de la literatura que fundó, en América Latina, la conciencia crítica de lo continental y de lo nacional, tal como aparece simbolizada, por ejemplo, en La ciudad letrada, de Ángel Rama. Esta conciencia ideológico-literaria de la modernidad latinoamericana (sus imágenes de la función intelectual y del pensamiento crítico) se ven hoy amenazadas por el efecto dispersivo de las redes globales cuyas imágenes massmediáticas fragmentan diariamente los trazados de integración de la nación y de la ciudadanía volviéndolos cada vez más difusos e inestables ${ }^{13}$. La literatura y los estudios literarios han debido acostumbrarse a este desplazamiento de protagonismo que coloca ahora lo visual y sus tecnologías de la imagen en el lugar antes ocupado por lo textual. La sustitución del espesor de lo verbal por la planitud de lo visual marcaría el triunfo irreflexivo de superficies sin hendiduras ni rasgaduras simbólicas, sólo hechas para consagrar "la desilusión de la metáfora ${ }^{14}$, al eliminar todas las marcas de profundidad (el enigma del pliegue, los dobleces de la multivocidad) que asociaban lo literario a sutiles protocolos de desciframiento estético.

Pero los estudios literarios han resentido, además, los efectos de otra confusión. Se han visto afectados por el gesto que realizaron los estudios culturales de amplia y extender la noción de "texto" a cualquier práctica social - o red articulada de mensajes - sin precisar la distinción entre "narración" (volumen) e "información" (superficie) que antes separaba lo directo de lo indirecto, lo literal de lo metafórico, los trámites simplemente decodificadores de la comunicación de los complejos juegos interpretativos de la simbolización estética.

El "giro lingüístico" que llevó la noción de texto a desbordar las fronteras de exclusividad de lo consagradamente literario para abarcar ahora

13 Al reflexionar sobre los cambios ocurridos en el diseño que asociaba el proyecto de las humanidades en América Latina a los modelos de identificación ciudadana, J. Ramos dice: "en este fin de siglo, marcado por la globalización distintiva de las sociedades mediáticas, acaso las formaciones sociales, no requieran ya de la intervención legitimadora de esos relatos modeladores de la integración nacional, en la medida en que el Estado se retrae de los contratos republicanos de la representación del "bienestar común" y en que los medios de la comunicación masiva y el consumo entretejen otros parámetros para la identificación ciudadana y sus múltiples exclusiones". Julio Ramos, "El proceso de Alberto Mendoza: poesía y subjetivación”, en Revista de Crítica Cultural $N^{o} 13$, noviembre de 1996, Santiago, p. 34.

14 Jean Baudrillard, La transparencia del mal, Barcelona, Anagrama, 1991, p. 14. 
cualquier práctica de discurso, nos ha traído el beneficio de una mirada teórica sobre lo social más atenta al detalle de cómo signos, códigos y representaciones, van urdiendo su trama simbólica, discursiva e institucional. Pero, por otra parte, esta apertura sin límites del Texto (en el sentido barthesiano de la palabra) a la «textualidad de cualquier práctica significante ha suprimido la necesidad de discriminar entre «texto»y «discurso», y también ha disuelto la especificidad de lo estético-literario en torno a la cual giran los estudios de la literatura. La semiotización de lo cotidiano social que nos llama a descifrar los artificios retóricos de una moda vestimentaria o de un programa televisivo con las mismas técnicas con las que, antes, analizábamos un poema o una novela, ha subordinado la pregunta por el valor de lo artístico y de lo literario "al punto de vista relativista de la sociología de la cultura ${ }^{15}$ : un punto de vista que admite comentarios sobre los efectos institucionales vista que admite comentarios sobre los efectos institucionales de produccióncirculación-recepción de las obras, pero que no nos permite dejarnos sorprender por la voluntad de forma y estilo que define las tomas de partido ideológico-críticas con las que cada obra elige oponerse a otras apostando a determinados valores de significación. La sociología de la cultura -cuyo registro predomina ampliamente en varias regiones del mapa académico de los estudios culturales- falla en hacerse cargo de la disputa de fuerzas entre lo ideológico, lo crítico y lo estético, cuando es precisamente esta tensionalidad la que dramatiza el arte en su apuesta valórica contra «el relativismo estético, cargado de indiferencia» ${ }^{16}$ que fomentan el pluralismo en serie del mercado y la industria culturales. La sociología de la cultura y los estudios culturales trivializaron la reflexión sobre los textos y sus estéticas al desatender el valor de la diferencia entre «texto»y «discurso»y al renunciar a especificar por qué ciertos lenguajes indirectos (llenos de ambigüedad y multivocidad) dicen lo que

15 Beatriz Sarlo, “Los estudios culturales y la crítica literaria en la encrucijada valorativa”. En Revista Cultural, No 15, noviembre de 1997, Santiago, p.36.

En la línea de Adorno para quien "una estética valorativamente neutra es un contrasentido", B. Sarlo argumenta a favor de los valores diciendo lo siguiente: "si la sociología de la cultura logra desalojar una idea bobalicona de desinterés y sacerdocio estético, al mismo tiempo evacua rápidamente el arfflisis de las resistencias propiamente estéticas que producen la densidad semántica y formal del arte. El problema de los valores es liquidado junto con los mitos de la libertad absoluta de la creación. La perspectiva sociológica disuelve la buena conciencia autojustificatoria, pero también corroe la densidad de las razones del arte». Beatriz Sarlo, Escenas de la vida posmoderna, Buenos Aires, Ariel, 1994, p. 156.

16 Theodor W. Adorno, Teoría estética, Madrid, Taurus, 1992, p. 367. 
dicen, con la intensidad formal y semántica de un más completamente irreductible a la practicidad comunicativo del signo que sólo transporta el valor-información del conocimiento.

La crisis del paradigma de lo literario, exacerbada por los flujos mediáticos de la cultura audiovisual, ha motivado la interrogante -formulada por J. Beverley- de saber «qué pasará cuando la literatura sea simplemente un discurso entre muchos» ${ }^{17}$, es decir, cuando se disuelva enteramente la frontera entre el lenguaje ordinario del mensaje instrumental y la poética del lenguaje que carga el signo de autorreflexividad y de plurivocidad. Es decir, cuando todo lo hablado y lo escrito terminen uniformándose bajo el mismo registro vanalizado de una mortal desintensifícación del sentido; un registro en el que la palabra habrá dejado de ser teatro o acontecimiento para volverse simple moneda de intercambio práctico ya carente de todo brillo, fulgor o dramaticidad. Esta pregunta por el destino de lo estético-literario en cuanto dimensión figurativa de un signo estallado (difractado y plural) capaz de criticar la homogeneidad de las hablas meramente notificantes que forman la masa comunicológica, también concierne la suerte de la escritura crítica hoy amenazada por la dominante instrumental de un saber práctico que censura los pliegues autorreflexivos de la escritura en cuya reserva se trama la relación entre sujeto, lengua y malestar crítico $^{18}$

\section{Las políticas del acto crítico}

El leitmotiv del «trans» («más allá de», 'del otro lado», «a través de», etc.) hoy recorre múltiples latitudes de la cultura académica para hablarnos de los cruces de fronteras, de las migraciones de identidades y de las

17 John Beverley, “HHay vida más allá de la literatura?”, en revista Estudios, $N^{\circ}$ 6, 1995, Caracas, p. 39

18 N. Casullo plantea que, para que los estudios culturales sean algo más que meras "asesorías a eventuales administraciones" de lo real en su dimensión más constreñidamente adaptativa, hace falta que reflexionen sobre "la disolución de un paradigma crítico" que enlazaba "la amenaza, el drama y las armas de la crítica" y cuya memoria hace falta "como problemática cultural... que no concilia con lógicas, lenguajes y horizontes tecno - instrumentales de una dominante de la cultura... donde todo aparece como vacuamente decible, transparentaba: pseudocrítica. Y donde la cultura instituida, progresado", vencedora, ofrece afirmativamente, en cada encrucijada, todas las palabras para explicar «el mundo». Nicolás Casullo, "Investigaciones culturales y pensamiento crítico", en revista Sociedad, $N^{o}$ 5, octubre de 1994, de la Facultad de Ciencias Sociales de la Universidad de Buenos Aires, p. 83. 
hibridaciones del conocimiento que están desplazando y reformulando los lugares geográficos, las clases sociales, los géneros sexuales y los saberes teóricos. Y los estudios culturales recogen, en su primer diseño, el impulso crítico de esta diagonalidad de cortes trazados en el mapa de las disciplinas tradicionales ${ }^{19}$. Pero la rápida academización del «trans» nos está diciendo que ya no es tal la incomodidad del-no refugio exaltada por esta primera voluntad crítica de nomadismo e itinerancia que señala el prefijo en contra de las formaciones sedentarias del saber institucional. Lo venido de otra parte y la alteridad crítica de los saberes que nacieron batallando contra la centralidad académica estarían hoy reintegrándose (al menos en la academia internacional) a un standard discursivo que administra «los efectos políticos institucionales de la inscripción del trabajo intelectual en el interior de la academia ${ }^{20}$ por medio del idioma profesionalizante de la crítica universitaria.

La transdisciplinariedad es una de las reglas teóricas que hoy impulsa los sistemas de conocimiento a querer extender y diversificar el campo de sus objetos de estudio para mejorar su comprensión de una realidad crecientemente móvil y compleja. Pero la mayor pluralidad de objetos a estudiar que los estudios culturales buscan conquistar, no siempre implica una reflexión sobre cómo pluralizar los modos de configuración discursiva del saber para que las palabras de lo nuevo no sigan cautivas de los viejos moldes de exposición. Es como si la nueva zona de libre comercio entre las disciplinas anunciada por el método de la interdisciplinariedad, se conformara simplemente con ordenar una suma pacífica de saberes complementarios destinados a integrar una nueva totalidad de conocimientos más abarcadora y funcional que deja finalmente intocados los contornos de cada saber heredado. Sin embargo, Roland Barthes ya

19 J. Ramos argumenta a favor del potencial crítico de los estudios culturales en los siguientes términos: «en la medida en que cortan diagonalmente el marco epistémico de las disciplinas, los estudios culturales suponen el cuestionamiento, a veces radical, del principio de autonomía -el principio de inmanencia que regula la validación de enunciados producidos por los campos racionalizados del saber moderno- con efectos tanto en las estrategias para el recorte de nuevos objetos de investigación y diseño curriculares, como en las concepciones de la compleja relación entre el saber y el poder que sobre determina las investigaciones mismas», Ramos, op. cit., p. 36.

20 Habla P. Bové de cómo la profesionalización académica del trabajo crítico hace que "los críticos llamados de oposición manejen 'profesionalmente' el pequeño valor significante o ‘función de oposición' y 'transforman los valores intelectuales en capital económico y social' de acuerdo a los altos índices de 'mercantilización y fetichismo dentro de las profesiones' que afectan el valor contestatario del discurso critico". Bové, op. cit., pp. 17-18. 
nos prevenía de que la interdisciplinariedad «no -puede llevarse a cabo por la simple confrontación de saberes especiales; la interdisciplinariedad no es una cosa reposada: comienza efectivamente... cuando se deshace la solidaridad de las antiguas disciplinas, quizás hasta violentamente... en provecho de un objeto nuevo, de un lenguaje. nuevo» ${ }^{21}$.

La formalización académica de la transdisciplinariedad llevada a cabo por buena parte de los estudios culturales ha terminado borrando de sus procesos de reorganización del saber lo que Barthes llamaba «el malestar de la clasificación.» ${ }^{22}$, es decir, la experiencia crítica de un desajuste necesario de tener siempre en cuenta para conjurar el peligro de que se reinstalen nuevas programaticidades de conocimiento cuando la renovación de los objetos de estudio termina complaciendo el llamado técnico a sólo producir un nuevo saber-en-orden (un saber que reclasifica) sin que la lengua encargada de transmitir ese saber acepte dejarse interrogar por la fuerza extrañante de lo desclasificado, de lo inclasificable, que encuentra su lugar en el destramar y retramarse de la escritura crítica.

Los estudios culturales nacieron con la idea de mezclar, colaborativamente, la pluridisciplinariedad (combinación plural de saberes flexibles) y la transculturalidad (apertura de las fronteras del conocimiento a problemáticas hasta ahora marginadas del paradigma monocultural de la razón occidental-dominante). Responden así a los nuevos deslizamientos de categorías entre lo dominante y lo subalterno, lo masculino y lo femenino, lo culto y lo popular, lo central y lo periférico, lo global y lo local, que recorren hoy las territorialidades geopolíticas, las simbolizaciones identitarias, las representaciones sexuales y las dios culturales reformulan así clasificaciones sociales. Los estudios culturales reformulan así un nuevo proyecto democratizador de transformación académica que permite leer la subalternidad (exclusiones, discriminaciones, censuras, periferizaciones) en los cruces de «un amplio rango de disciplinas académicas y de posiciones sociales ${ }^{23}$. Es decir que los estudios culturales -en su versión más fuertemente motivada por lo que J. Beverley llama una "vocación política" ${ }^{4}$ pretenden, al menos, dos cosas: 1) desjerarquizar el

21 Roland Barthes, El susurro del lenguaje, Barcelona, Paidós, 1987, p. 73. 
conocimiento y modificar las fronteras entre disciplinas para producir un nuevo saber más plural y flexible, es decir, un saber mezclado que permita comprender más adecuadamente las nuevas realidades -híbridas- de un paisaje social en extensa mutación de categorías e identidades, y 2) no sólo estudiar este paisaje, sino que intervenir en él, haciendo explícito, contra la voluntad de autonomía de las disciplinas tradicionales, su compromiso con los movimientos sociales y las prácticas culturales de sujetos contrahegemónicos (post-colonialismo, feminismo, multiculturalismo, etc.). Esta vocación política de los estudios culturales los llevó a construir una especie de «saber orgánico" (Stuart Hall) destinado a fortalecer la demanda de- ciudadanía de los grupos minoritarios en un contexto de transformaciones democratizadoras, y también a rearticular políticamente las significaciones culturales que plantean sus nuevas condiciones de emergencia social en el terreno de la academia.

La idea de un saber que usa la interdisciplinariedad para combinar diferentes modelos de análisis de las nuevas problemáticas de género, multiculturales, postcoloniales, etc., nos habla de un saber constructivo y organizativo, de un saber que busca perfeccionar la utilidad de ciertos instrumentos de reflexión teórica y social para hacerlos «funcionales $»^{25}$ a ciertas dinámicas de cambio académicas y extra académicas. En su afán de «criticar a las disciplinas, democratizar estructuras, modificar requisitos, desmantelar el canon, crear nuevos espacios para trabajar con libertad $»^{26}$, los estudios culturales pelean por la efectividad práctica de cambios que deberán modificar las reglas más conservadoras de la enseñanza universitaria tradicional que siguen gobernando departamentos y programas. «Democratizar el conocimiento» (Beverley) significa, entonces, favorecer la incorporación plural de saberes hasta ahora desvalorizados por las jerarquías de conocimiento de la cultura canónica:

23 John Beverley, "Writing in reverse: on the project of the Latin Amencan Subaltern Group", en Disposition XIX, 1994, University of Michigan, p. 285.

24 J. Beverley, "Estudios culturales y vocación política", en Revista de Crítica Cultural, $\mathrm{N}^{\mathrm{o}}$ 12, julio de 1996, Santiago.

25 El comentario de B. Sarlo, referido a esta funcionalidad de los estudios culturales, dice lo siguiente: "en los últimos diez o quince años, los estudios culturales aparecieron como una solución apropiada para los rasgos de la nueva escena. Sin voluntad de extremar la caracterización, diría que movimientos sociales y estudios culturales fueron compañeros de ruta extremadamente funcionales a la transición democrática, por una parte, y al naufragio de las totalizaciones modernas, por la otra.", Sarlo, "Los estudios culturales y la crítica literaria en la encrucijada valorativa", op. cit. p. 33. 
saberes cuyo potencial emancipatorio es capaz de desbordar el texto académico con nuevas energías de transformación social en conexiones de flujos teórico-políticos con el afuera vivo de la universidad. Y no cabe duda que el movimiento democratizador de los estudios culturales que reorganiza el conocimiento en complicidad de voces con identidades hasta ahora subrepresentadas por el canon de la academia metropolitana, ha alterado el sistema de autoridad de la institución universitaria con su revalorización de lo no-central y de lo contrahegemónico. Pero es también cierto que la practicidad de saber de los estudios culturales tiende generalmente a anular la tensión entre sujeto, teoría y escritura, que debería hacer vibrar la reflexión sobre el texto crítico hoy reprimida por la dominante sociológica de las nuevas investigaciones académicas.

F. Galende discute este punto ${ }^{27}$ afirmando que los estudios culturales no harían, sino poner a circular lo otro en el mercado de lo conocido, "destituir la heterogeneidad de lo otro, el episodio inaudito de otro, todo lo que ese otro es cuando no es sólo su vida útil» para finalmente «citarlo a comparecer en la categoría ${ }^{28}$ y domesticar así su surgimiento rebelde con un reordenamiento funcional a las burocracias discursivas de la crítica que hacen progresar el conocimiento de lo nuevo en la exclusiva dirección de significaciones, todas ellas, calculables y administrables, en lugar de abrirlo al riesgo de lo intempestivo. Según F. Galende, la crítica académica institucionalizada por los estudios culturales sólo les permitiría ilustrar «la metáfora oficial de un inerte realismo de época ${ }^{29}$ «que busca ajustar su saber a los cambios, en lugar de potenciar el cambio como la fuerza de des-ajuste que debe sacudir la lengua normalizada de conocimiento y su disciplina académica $»^{30}$. Es cierto que muchos exponentes de los estudios culturales creen hacer acto de conocimiento al sólo describir lo real transformado, sin nunca preguntarse por el efecto de disrupción que deberían causar las transformaciones en el interior de la lengua misma, perturbando radicalmente la adecuación satisfecha entre razón, método y objetividad con todo lo que separa, inquieta, divide y conmociona los léxicos demasiado en regla consigo mismos, con el

26 John Beverley, "Estudios culturales y vocación política", p. 48

27 Remito a la réplica del autor que polemiza con la postura de Beverley sobre los estudios culturales: Federico Galende, "Un desmemoriado espíritu de época: tribulaciones y desdichas en torno a los estudios culturales", en Revista de Crítica Cultural, $N^{\circ} 13$, noviembre de 1996, Santiago, p. 52. 
verosímil dominante de la academia y sus índices de legibilidad mayoritariamente aprobados. Quizás una posible diferencia entre los estudios culturales y la crítica cultural -entendida, esta última, como «crítica de la crítica»-, tenga que ver con esta tensión entre el saber explicativo que formula y expone las razones de por qué nuestro presente es como es, y el saber interrogativo que no se conforma con estas demostraciones, sino que busca perforar el orden de sus pruebas y certezas con el tajo (especulativo) de la duda, de la conjetura o bien de la utopía hechas, en cada caso, reclamos de escritura contra la didáctica del saber conforme con sólo aplicar técnicas enseñantes.

Pero tampoco basta la idea de un saber que se contorsiona en los arabescos de la duda y del eterno preguntar(se), sin correr el riesgo de una afirmación o de una negación que, por provisorias que sean, se atrevan a decidir: a ejercer la responsabilidad práctica de un acto de sentido. Perderse en el infinito deslizarse de las significaciones frustrando todo posible encuentro del significante con el significado, conspira obviamente contra la posibilidad de que el saber pueda ejercer una acción transformadora sobre las estructuras materiales de la institución ${ }^{31}$. Tal acción necesita que el pensamiento dubitativo salga de su reserva ensimismada y se pronuncie a favor o en contra de ciertas decisiones, interrumpiendo el suspenso de su limitada cadena de indefiniciones para detenerse en algún sitio ubicable desde el cual tirar líneas, marcar posiciones, señalizar y comunicar los cambios. El momento organizativo de cualquier lucha académico-institucional depende de la capacidad que tiene el saber de operar sobre tramas concretas de sentido y referencias, para intervenir el soporte de la institución en su materialidad concreta ${ }^{32}$, y el «deseo llamado estudios culturales» (Jameson) no podría concretarse sin pasar por estos manejos prácticos. El gesto a imaginar sería entonces un gesto doble, combinado: un gesto que, por una parte, se atreve a materializar

30 Decía M. de Certeau, a propósito de los peligros que representan, para cualquier especialista, "la irrupción de lo impensado: algún elemento tácito agitado invalida las herramientas mentales elaboradas en función de una estabilidad. Pero los instrumentos también formaban parte de lo que se ha agitado". Michel de Certeau, La toma de la palabra, y otros escritos políticos, México, Universidad Iberoamericana, 1995, p. 30

31 Dice P. Bové: “como observa Gramsci, las fuerzas contrahegemónicas necesitan siempre una estructura institucional para orientar la resistencia y reorganizar las posibilidades culturales" en nuevas direcciones; el desafío crítico consistiría en conectar la dinámica de los cambios de los cambios con dicha estructura sin dejar que lo ya instituido en ellos la atrape y la inmovilice. Bové, op. cít., p. 71. 
el cambio pasando necesariamente por la concreción de operaciones localizadas en un marco institucional, y que, por otra parte, se mantiene vigilante frente al peligro de que inadvertidas conformismos de estilo terminen llevando la lengua y el saber de lo «nuevo» a sólo ilustrar el realismo académico de las políticas del cambio. Gesto doble sobre el cual medita Derrida al evocar la tensión entre filosofía e institución, cuando afirma que «lo extrainstitucional debe tener sus instituciones sin pertenecerles», y cuando se pregunta: “¿cómo conciliar el respeto del límite institucional con su transgresión?, ¿cómo conciliar la identidad localizable con la ubicuidad desbordante?"33, siendo ambas dimensiones igualmente necesarias para construir una política del acto crítico.

Las relaciones entre la institución académica y sus bordes; entre el saber centralizador y las fuerzas de dispersión; entre la ritualización del "Discurso Universitario" y sus «otros» precarios e híbridos, no son relaciones fijas, sino relaciones móviles y cambiantes, hechas de líneas y de segmentos variables tanto en su consistencia de enunciados como en el equilibrio de sus ubicaciones. Revisar este diagrama de fuerzas para calcular el modo en que los cambios efectuados en el interior de la academia (llámense estudios de género o estudios culturales) son capaces de afectar -y en qué grado- su máquina del conocimiento; examinar los conflictos y antagonismos de saberes que emergen de las fisuras de autoridad del discurso centrado, es parte de lo que la misma crítica cultural propone como trabajo desconstructivo, es decir, como un trabajo que no se resume a un simple método de análisis de los textos sino que busca intervenir las formas y los soportes de relaciones -prácticas e institucionales- de los discursos. Razón por la cual es sólo la práctica crítica de la teoría ${ }^{34}$ la que puede decidir, situacionalmente sobre el valor de los desarreglos de enunciados que su discurso pretende operar en el formato institucional del saber académico.

32 Al precisar la distinción entre "institucionalización” y “codificación”, S. Hall precisaba: "Estoy a favor de la institucionalización porque se necesita pasar por el momento organizacional -la larga ruta a través de las instituciones para... construir alguna forma de proyecto intelectual colectivo", en Stuart Hall, Critical Dialogues in Cultural Studies, edit. By David Morley and Kuan-Hsing Chen, london, Routledge, 1996, p. 149. (La traducción es mía).

33 Jacques Derrida, "Les antinomies de la discipline philosophique-Lettre préface", en La Grève des Philosophes (Ecole et philosophie), París, Editions Osiris, 1986, p. 15. (La traducción y los destacados son míos). 